\title{
Interaction of Coal Humic Acids with Fungal Laccase
}

\author{
Natalia A. Kulikova ${ }^{1,2 *}$, Valentina N. Davidchik ${ }^{2}$, Eugenia A. Tsvetkova ${ }^{3}$, Olga V. Koroleva ${ }^{2}$ \\ ${ }^{1}$ Department of Soil Science, M.V. Lomonosov Moscow State University, Moscow, Russia \\ ${ }^{2}$ A.N. Bach Institute of Biochemistry, Moscow, Russia \\ ${ }^{3}$ N.D. Zelinskii Institute of Organic Chemistry, Moscow, Russia \\ Email: ${ }^{*}$ knat@darvodgeo.ru
}

Received March 4, 2013; revised April 4, 2013; accepted May 4, 2013

Copyright (C) 2013 Natalia A. Kulikova et al. This is an open access article distributed under the Creative Commons Attribution License, which permits unrestricted use, distribution, and reproduction in any medium, provided the original work is properly cited.

\begin{abstract}
Humic acids (HA) are one of the main environmental factors controlling the fate and behavior of the compounds released into the environment. In particular, they are universally considered of great importance in determining soil extracellular enzyme activity and stability via association with essential soil enzymes. The objective of this study was to investigate the interaction of coal HA with an extracellular multicopper oxidase laccase (EC 1.10.3.2) that catalyze the oxidation of a wide range of reducing substances in the environment. Using size-exclusion chromatography analysis and monitoring laccase activity, the formation of a stable and an enzymatically active complex between HA and laccase was shown. Basing the data obtained by isoelectric focusing of HA-laccase complex, non-covalent character of laccase association with HA was considered and binding of laccase to HA by weak dispersive forces such as van der Waals, hydrophobic, $\pi-\pi, \mathrm{CH}-\pi$ and others was hypothesized.
\end{abstract}

Keywords: Humic Acids; Laccase; Activity; Size-Exclusion Chromatography; Complexes; Isoelectric Focusing

\section{Introduction}

Humic substances (HS) are ubiquitous natural compounds comprising the major component of soil organic matter and sediments, as well as aquifers [1-3]. By the chemical nature HS can be considered to be irregular polymers of aromatic polyhydroxyl carbonic acids [3], and the peculiarity of the structure of HS consists of a coexistence of both polar and hydrophobic environments in the same molecule. As a result, HS are able to bind both polar and hydrophobic organic compounds and inorganic ions as well. Thus, HS are one of the main environmental factors controlling the fate and behavior of the compounds released into the environment. In particular, they are universally considered of great importance in determining soil extracellular enzyme activity and stability via association with essential soil enzymes such as ureases, proteases, phosphatases, hydrolases, laccases, and peroxidases, which have been detected in soil extracts as complexes with HS $[4,5]$. Contrary to the extracellular enzymes incorporated into a soil mineral matrix, where they often loose their activity, humus-immobilized enzymes can frequently retain their activity and display stability against environmental stresses.

\footnotetext{
${ }^{*}$ Corresponding author.
}

Laccases (EC 1.10.3.2) are extracellular multicopper oxidases that catalyze the oxidation of a wide range of reducing substances with the concomitant reduction of $\mathrm{O}_{2}$. Because of their capability of oxidizing aromatic compounds, such as phenols and anilines, laccases have promising potential as industrial enzymes for various applications, such as wood fiber modification, biosensor construction, and water and soil remediation [6-10]. Recently laccase-based biocatalysis has been expanded, with the aid of small "mediators", to pulp delignification [1113], textile dye bleaching [14,15], polycyclic hydrocarbon degradation [16-20], destruction of pesticide, insecticide, or chemical warfare [21-23], and organic synthesis $[24,25]$. Nowadays a special attention is paid to laccase in relation to so-called enzymatic treatment, which is currently considered as an alternative method for the removal of toxic xenobiotics from the environment $[8,10]$. Enzyme-mediated transformation reactions may result in formation of compounds where xenobiotics bind covalently to HS via oxidative coupling [26,27].

Despite the abundance of promising experimental data, a number of limitations still restrict the use of laccase to detoxify xenobiotics. One of them is a lack of knowledge in the field of laccase interaction with HS, which can influence both on the enzyme activity and stability in the 
environment. Only a few studies are available now in literature [28,29], and an investigation of association of HS with laccase is therefore of great interest. The objective of this research was to investigate laccase interaction with $\mathrm{HS}$ in a model system containing laccase and coal humic acids (HA) and to get insight into the nature of HA-laccase complex.

\section{Experimental}

\subsection{Humic Acids}

Humic acids (HA) used in this study was a commercial preparation of leonardite HA "Powhumus" (Humintech, Germany). Elemental analysis of HA was determined with a Carlo Erba Strumentazione analyzer and showed that HA contained (on ash-free and moisture-free bases) $45.9 \% \mathrm{C}, 3.4 \% \mathrm{H}$, and $1.6 \% \mathrm{~N}$. Ash content was $1.1 \%$. Content of carboxylic and phenolic groups determined using potentiomentric titration technique was 2.9 and 3.0 mekv/g, respectively [30].

\subsection{Laccase Isolation and Characterization}

For this study laccase form the strain of Trametes hirsuta (Wulf.:Fr.) Pil. 072 was used. The fungal strain was kindly provided by Komarov Botanical Institute (St. Petersburg, Russia) and cultivated as described earlier [31]. Extracellular laccase was isolated from the culture medium and purified in accordance with [32]. The control of laccase homogeneity was carried out with polyacrylamide gel (PAAG) electrophoresis under non-denaturing conditions as described in [33]. The pH optima of the major isoenzyme determined using pyrocatechol as substrate was 4.5 [32].

\subsection{HA-Laccase Complexes Preparation and Monitoring}

The HA-laccase complexes were prepared by incubation $\left(27^{\circ} \mathrm{C}, 72\right.$ hours) of laccase and HA together at concentrations of 100 and $40 \mathrm{mg} \cdot \mathrm{l}^{-1}$, respectively. A $50 \mathrm{mM}$ potassium phosphate buffer at $\mathrm{pH} 5.0$ or 6.5 was used as a background electrolyte. In parallel, control solutions of laccase and HA solely were incubated under the same conditions. Because of the observed biodegradation of laccase (data not shown) toluene was added to the solutions to suppress microbial activity [34]. After 6, 24, 48, and 72 hours of incubation solutions were sampled for size-exclusion chromatography analysis. Additionally, during the incubation laccase activity and protein concentrations were monitored at regular intervals (after 1, 3, 6, 9, $12,24,48$ and 72 hours). For isoelectric focusing laccase with HA were incubated at the same conditions, but for longer period of time (168 hours) and using higher concentrations of the compounds. Namely, concentration for laccase was $1000 \mathrm{mg} \cdot \mathrm{l}^{-1}$ and for HA $400 \mathrm{mg} \cdot \mathrm{l}^{-1}$.

\subsection{Fractionation of the HA-Laccase Complexes by Size-Exclusion Chromatography (SEC)}

SEC analysis was performed according to [35]. SEC system Abimed (Gilson, France) was equipped with online UV detector and included HPLC pump, auto sampler, and glass column. The column $25 \mathrm{~mm} \times 20 \mathrm{~cm}$ packed with Toyopearl TSK HW-55S gel (Toso Haas, Japan) was used for separation. The $0.028 \mathrm{M}$ phosphate buffer ( $\mathrm{pH}$ 6.8) was used as a mobile phase. The flow rate was set at $1 \mathrm{ml} \cdot \mathrm{min}^{-1}$. The absorbance of eluate was detected at $254 \mathrm{~nm}$. A void volume $\left(\mathrm{V}_{0}=19.2 \mathrm{ml}\right)$ and a total permeation volume $\left(\mathrm{V}_{\mathrm{t}}=74.5 \mathrm{ml}\right)$ of the column were determined using Blue Dextran 2,000,000 and acetone, respectively. Sodium polystyrene sulfonates (PSS) of molecular weight of 2.29, 4.48, 14.00, 20.70, 45.10, and 80.84 kDa (Polymer Standard Service, Germany) were used as markers for molecular weight calculations. Data obtained was treated using approach published in [36]. To obtain laccase activity profiles of the HA-laccase complex 10-ml fractions were collected and analyzed for laccase activity.

\subsection{Study HA-Laccase Complex Formation by Isoelecric Focusing (IEF)}

To determine change of isoelectric point (pI) of laccase associated with HA compared to free laccase, IEF was carried out as described in [37]. Briefly, $20 \mu \mathrm{l}$ of solution of fresh prepared HA-laccase complex, HA-laccase complex after 72 or 168 hours of incubation, HA or laccase without added HA was sampled and directly loaded in a standard PAAG $(110 \times 120 \times 0.4 \mathrm{~mm}, \mathrm{~T}=7.5 \%, \mathrm{C}=$ $3 \%$ ) containing 3\% ampholytes $\mathrm{pH} 4.0$ - 7.0 (Iso-Lyte 4 7, ICN Biomedicals). $1 \mathrm{M} \mathrm{NaOH}$ and $1 \mathrm{M} \mathrm{H}_{3} \mathrm{PO}_{4}$ were used as cathodic and anodic buffers, respectively. IEF was conducted at constant power of $6 \mathrm{Wt}$ and temperature of $10^{\circ} \mathrm{C}$ during 1.5 hours. Gels were stained with a solution of Coomassie Blue R-250.

\subsection{Measurements of Laccase Activity}

The laccase activity was determined spectrophotometrically or polarographically. In case of spectrophotometric approach [32] laccase activity was measured by following the rate of oxidation of pyrocatechol to quinone by plotting the absorbance at $410 \mathrm{~nm}$ (A410) against time. A stock solution contained $10 \mathrm{mM}$ pyrocatechol in $0.1 \mathrm{M}$ sodium acetate buffer at $\mathrm{pH}$ 4.5. One unit of activity was defined as a change in A410 per min per mg of protein.

Polarographic assay of laccase activity was carried out using a Clark oxygen electrode in a hermetically sealed sample chamber (final volume $0.7 \mathrm{ml}$ ) at $25^{\circ} \mathrm{C}$. The en- 
zymatic reaction was initiated by the addition of laccase solution to $4 \times 10^{-5} \mathrm{M}$ syringaldazine (4-hydroxy-3,5dimethoxybenzaldehyde azine) in $0.1 \mathrm{M}$ sodium acetate buffer at $\mathrm{pH} 4.5$. Laccase final concentration in the sample chamber was $25 \mathrm{nM}$. The initial oxygen concentration was $260 \mu \mathrm{M}$ (according to the evaluation of the Henry coefficient). One unit of enzymatic activity was defined as the amount of laccase required for consumption $1 \mu \mathrm{mol} \cdot \mathrm{min}^{-1}$ of $\mathrm{O}_{2}$.

Protein concentration was measured with a use of bicinchoninic acid (BCA) protein assay kit (Pierce, USA).

\subsection{Statistical Data Treatment}

All results were presented as mean \pm SD. Comparison between two means was performed using unpaired Student's t-test. Differences were considered to be significant when $\mathrm{p}<0.05$.

\section{Results and Discussion}

\subsection{HA-Laccase Association}

Association of laccase with HA was monitored using
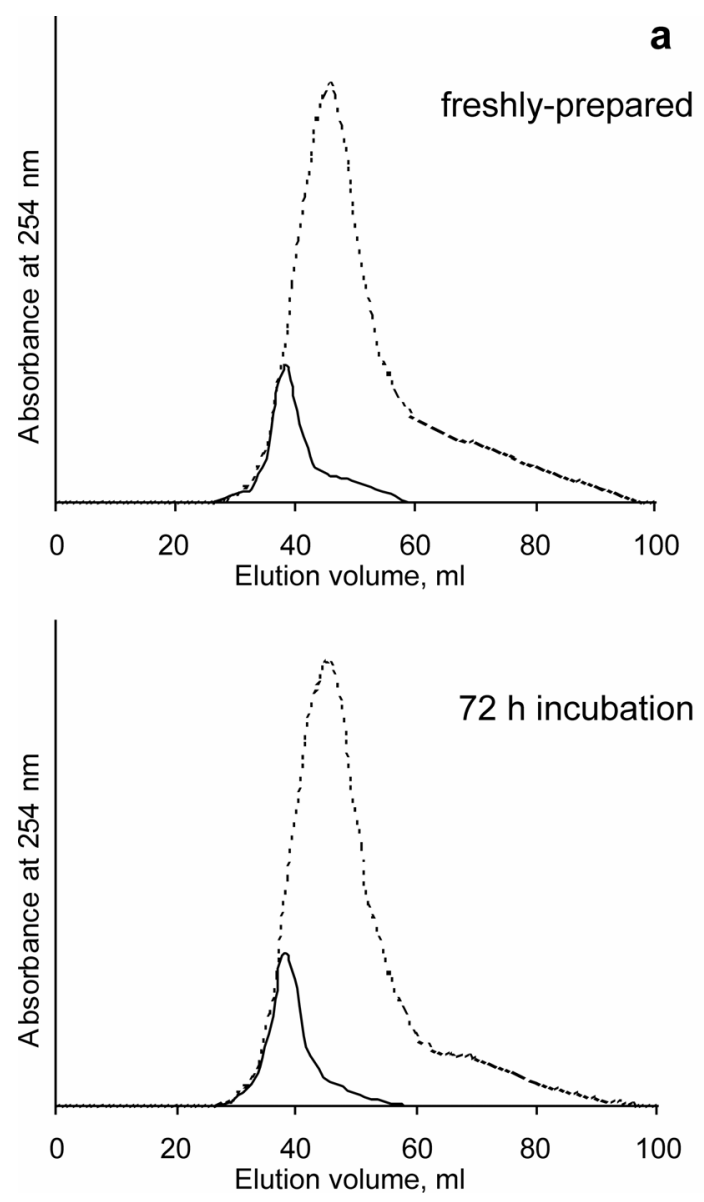

SEC. SEC-profiles of HA and laccase solely did not change within 72 hours (Figure 1) demonstrating their stability during the time of the experiment. Chromatograms of both HA and laccase exhibited a sharp single symmetric peak. This finding confirms that the SEC-fractionation was conducted under conditions appropriate for the substances under study, as no artifacts such as ionic exclusion or specific adsorption were observed [35,38]. That was also indicative for complete suppression of the surface negative charge of HA (ibid.). Observed values of elution volume for HA [45.4 ml] and laccase [38.4 ml] corresponded to the peak molecular weight (MW) values of 9.6 and $21.9 \mathrm{kD}$ respectively. The MW of laccase from $T$. hirsuta determined earlier using standard globular protein calibration kit was reported to be $55 \mathrm{kD}$ [39], what was considerably higher than obtained in our experiments. The observed variance in MW values can be attributed to the difference in SEC system such as the charge density of the used calibrants. In particular, in [35] it was shown that the smaller the charge density of the chosen calibrants, the higher the values of MW will be.

SEC-profiles of HA-laccase complexes at different $\mathrm{pH}$ are presented in Figure 2. The chromatograms consisted
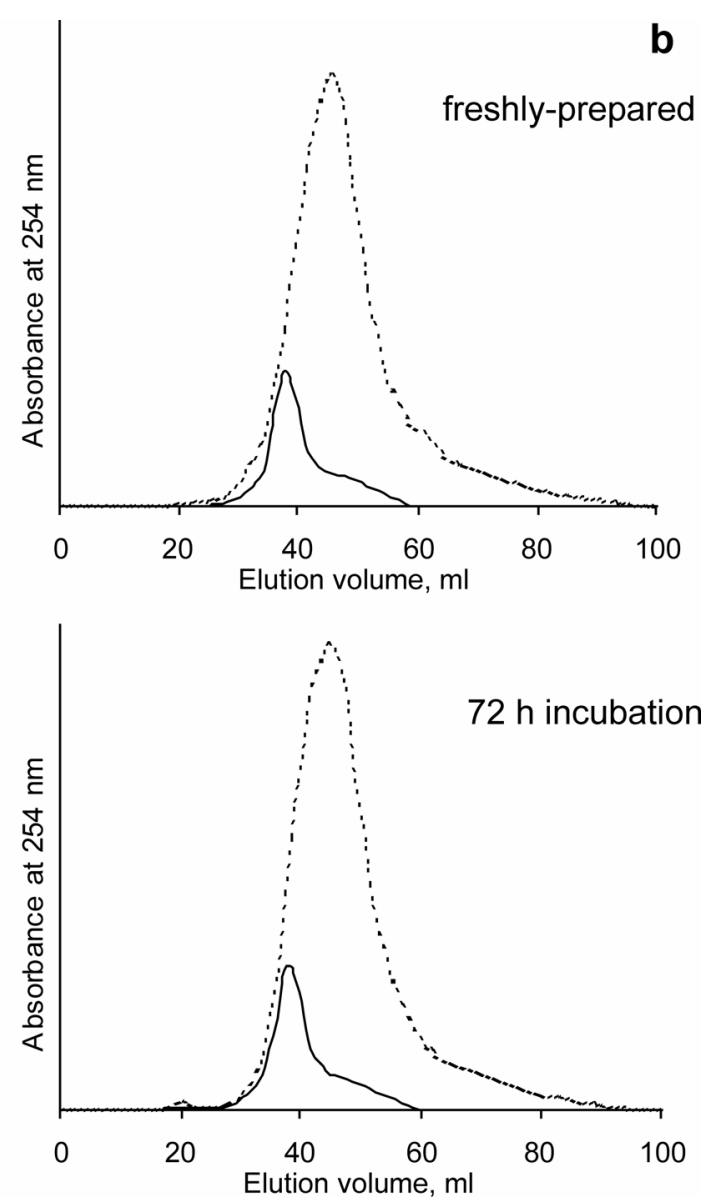

Figure 1. SEC chromatograms of laccase and HA solutions at pH 5.0 (a) and 6.5 (b) in fresh-prepared solutions and after 72 hours of incubation. Firm lines represent laccase, dotted lines represent HA. 

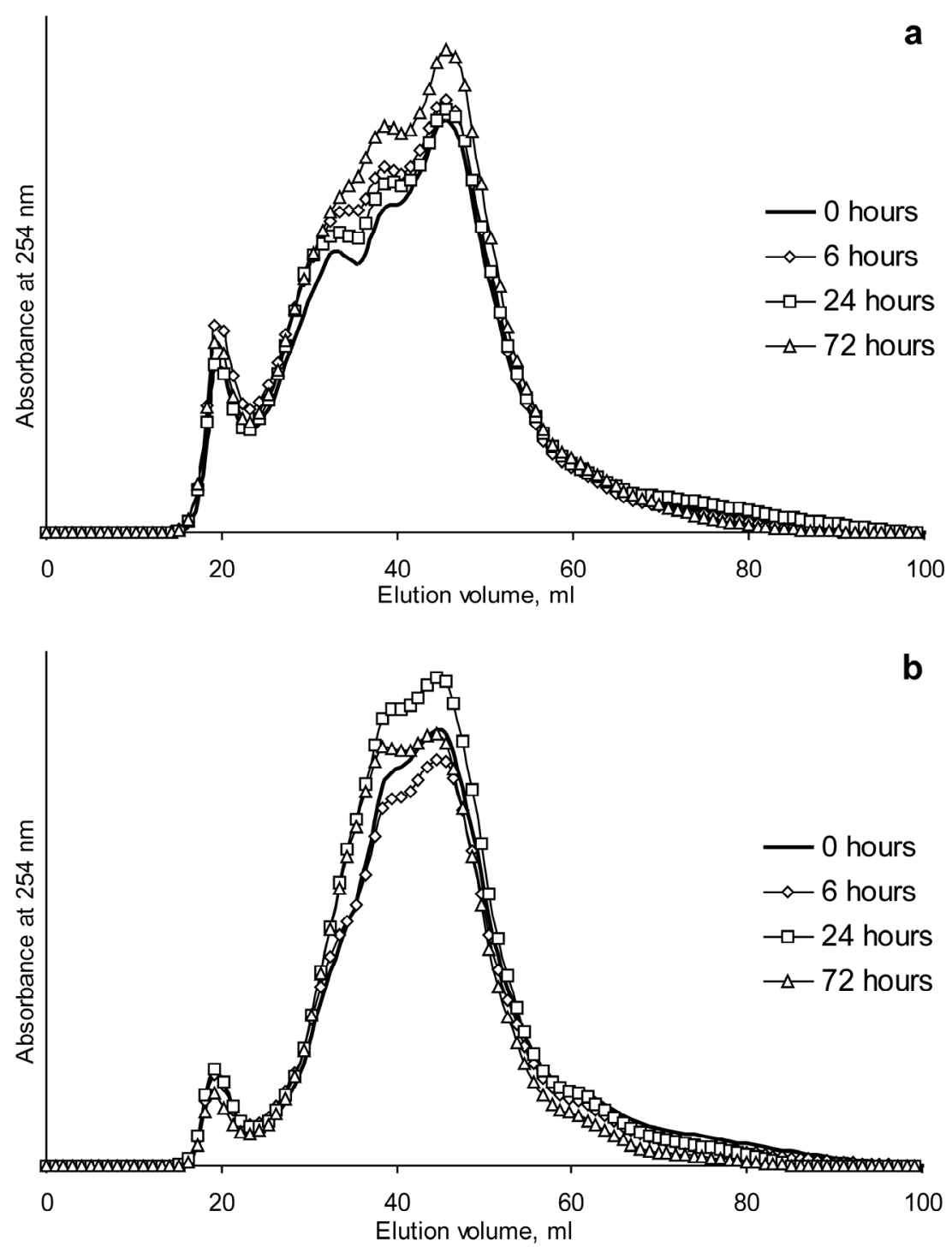

Figure 2. SEC chromatograms of HA-laccase complexes after different time of incubation at pH 5.0 (a) and 6.5 (b).

of the first sharp peak followed by $2-3$ diffused peaks. As it can be seen, profiles of HA-laccase complexes cannot be described as a superposition of SEC-profiles of these substances. Along with peaks corresponding to HA and laccase and additional peak at an elution volume equal to the $\mathrm{V}_{0}(19.2 \mathrm{ml})$ of the column appeared. Given that ionic exclusion arising from repulsive interaction between the charged analyte and the partially charged gel matrix can be excluded, a formation of HA-laccase complex with molecular weight larger that fractionation range of the SEC-system used should be proposed. Indeed, activity profile of laccase in the presence of HA obtained by SEC-fractionation of HA-laccase profile after 24 hours of incubation showed the main activity peak at the elution volume of about $20 \mathrm{ml}$ (Figure 3). This behavior was interpreted to be a result of the formation of a stable and enzymatically active complex between HA and lac- case.

Polymerization of HA in the presence of laccase could be also surmised to be responsible for the observed additional peak. Appearance of new HA peaks with corresponding peak MW of 18.8 and $40.9 \mathrm{kD}$ at $\mathrm{pH} 5.0$ (elution volumes 39.6 and $32.3 \mathrm{ml}$ ) or with $18.8 \mathrm{kD}$ at $\mathrm{pH} 6.5$ (elution volume $39.6 \mathrm{ml}$ ) was also evident for the formation of HA fractions with larger peak MW comparing with initial humic material. This is in agreement with recent results that have shown an increase in molecular size of humic matter following an oxidative polymerization reaction catalyzed by the peroxidase [40]. As laccase under study was demonstrated to have the maximum catalytic activity at $\mathrm{pH} 4.5$ [39], the enzymatic activity was therefore supposed was greater at $\mathrm{pH} 5.0$ than at 6.5. In comparison to $\mathrm{pH} 6.5$, the intensity of the additional peak was higher at $\mathrm{pH} 5.0$ (Figure 2). This finding could 


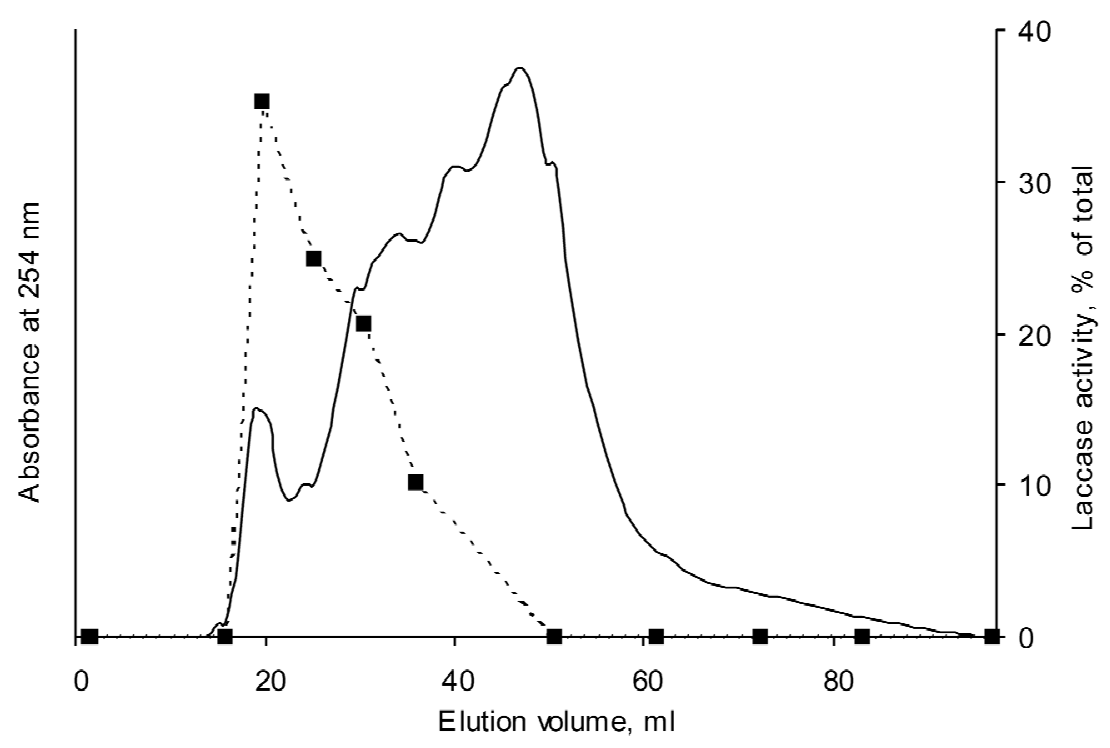

Figure 3. SEC chromatogram and activity profile of HA-laccase complex at pH 5.0 after 24 hours of incubation. Firm line represents absorbance profile, dotted line represents activity profile.

be attributed to the greater HA polymerization under conditions of the higher enzymatic activity of laccase. However, quantitative evaluations are prone to errors because of possible changes in the molar extinction coefficients of components in fractions belonging to different peaks.

During the experiment a slight increase in intensity of absorbance of the diffused peaks was observed. Assuming that chromophores possessing conjugated $\pi$-electron systems (e.g. $\mathrm{C}=\mathrm{C}-\mathrm{C}=\mathrm{C}, \mathrm{C}=\mathrm{C}-\mathrm{C}=\mathrm{O}$ and aromatic compounds) mainly determined UV absorptivity at $254 \mathrm{~nm}$, oxidation of HA in the presence of laccase following formation of quinonic structures from phenolic moieties in HA could be proposed. So, the observed polymerization of coal HA in the presence of laccase was possible due to the processes similar to the oxidative coupling of phenols.

Association of HA with laccase was supposed to alter pI of the enzyme due to formation of its complex with humics. Therefore, the IEF separation of the HA-laccase complex and laccase was conducted. The obtained results are presented in Figure 4. IEF showed no HA band under selected conditions, while for laccase a double band at $\mathrm{pH}$ ca 4.0 was observed reflecting the existence of two isoenzymes with close isoelectric points [39]. IEF of the blank solution containing laccase solely showed no changes in enzyme electrophoretic behavior during 7 days of incubation indicating laccase stability under selected conditions. It can be seen that over the experiment the $\mathrm{pI}$ of laccase in the HA-laccase complex did not change as compared to free laccase at both $\mathrm{pH}$ studied. In particular, neither appearance of an additional band nor its shift nor alteration in intensity of the bands was observed. This finding was an evidence of non-covalent character of laccase association with HA, as covalent bond formation would result in HA-laccase complex stable under IEF conditions. On the other hand, ionic interactions between HA and enzyme was supposed to be negligible under selected conditions as HA-laccase complex remained stable in SEC analysis where surface negative charge of HA was suppressed. The association between HA and laccase by weak dispersive forces such as van der Waals, hydrophobic, $\pi-\pi, \mathrm{CH}-\pi$ and others was therefore hypothesized.

\subsection{Dynamic of Laccase Activity in the Presence and Absence of Coal HA}

The study of laccase activity in the presence of HA has been carried out for 3 days and one could expect the interference of microorganisms in reaction mixture. To suppress microbial activity, toluene was added to the solutions, what resulted in inhibition of laccase activity in fresh prepared solutions both at $\mathrm{pH} 5.0$ and $\mathrm{pH} 6.5$ (Figure 5). The drop in enzyme activity comprised nearly $30 \%$ and $50 \%$ compared to laccase without added toluene at $\mathrm{pH} 5.0$ and 6.5 , respectively. This finding was in agreement with a generally accepted notion on an enzyme inhibition by organic solvents due to their interaction with the protein [41-43]. The investigations showed that at low and moderate concentrations (up to $3.5 \mathrm{M}$ ) of water-miscible solvents, the solvents caused a linear increase of the apparent Michaelis-Menten constant $\mathrm{Km}$ values for standard laccase substrates and rather low changes in the maximum reaction rate Vmax values. The authors supposed that organic solvents behaved like the simple competitive or mixed competitive inhibitors of 
a

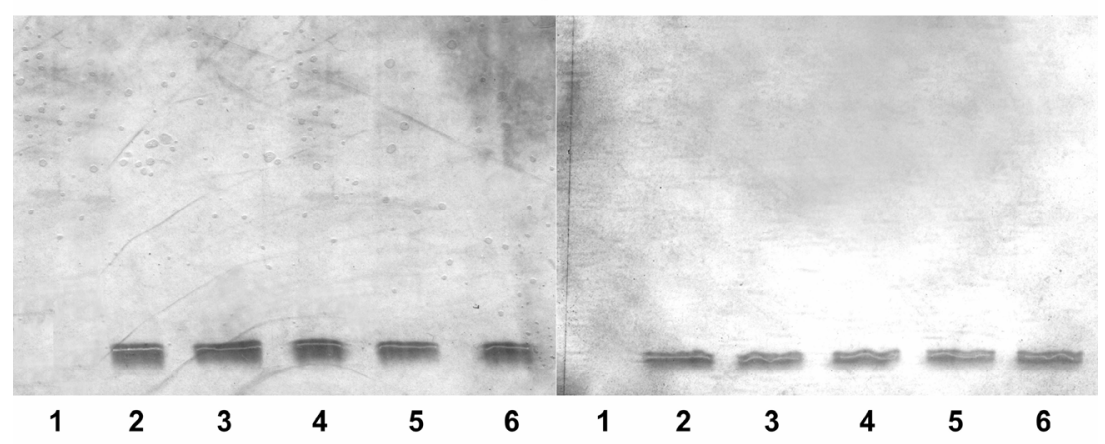

Figure 4. IEF analysis of HA, laccase and HA-laccase complex after different time of incubation at pH 5.0 (a) and pH 6.5 (b). 1 - HA, 2, 3 -laccase after 0 and 168 hours of incubation, 4, 5, 6 - HA-laccase complex after 0, 72, and 168 hours of incubation.
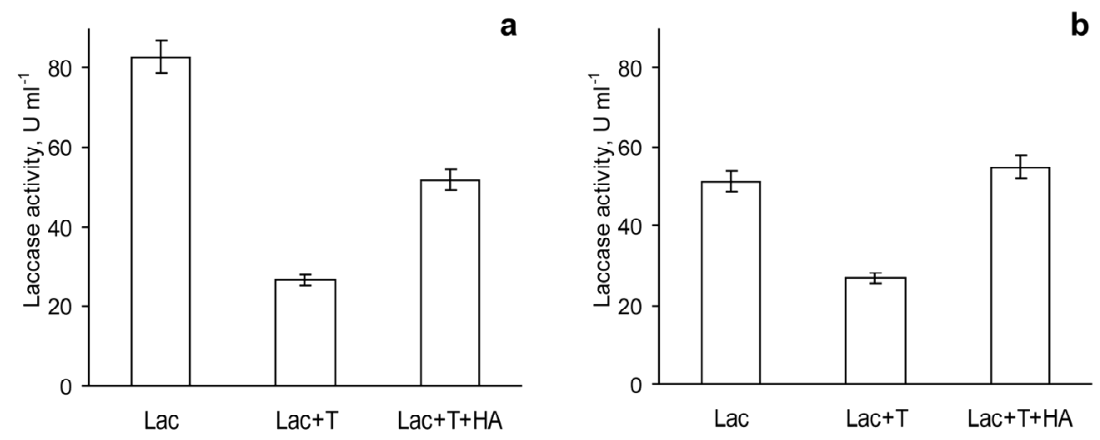

Figure 5. Activity of laccase solely (Lac), in the presence of toluene (Lac $+\mathrm{T})$ and in the presence of toluene and HA (Lac $+\mathrm{T}$ + HA) at pH 5.0 (a) and 6.5 (b). Bars represent standard deviations.

laccase $[42,43]$. Another possible reason for laccase inactivation could be a loss of water and/or unfolding of an enzyme in the presence of polar solvents [41]. Laccase from T. hirsuta contains 284 molecules of water according to crystallographic study and the first assumption is rather reasonable. Besides, the difference in optical spectra of laccase solely and laccase with toluene was insignificant (data not shown). Therefore, only the nearest surrounding of the laccase active center was supposed to be affected by toluene.

In this study, coal HA did not have a negative effect on laccase activity (Figure 5), what was in agreement with recently published data [44]. The finding, nevertheless, contradicted the reported data on the inhibitory effect of coal HA on laccase [29]. The authors proposed that the inactivation of laccase was mainly due to depletion of the copper ion from the active site of the enzyme. However, it is widely accepted that laccase can loose its activity because of dissociation of $\mathrm{Cu}$ only in the presence of a strong chelating agent under anaerobic conditions. Even for elimination of copper type 2 (the most easily eliminating copper ion from laccase) it is necessary to use guanidine chloride under denaturing condition followed by bathcuproine treatment $[45,46]$. In this study interaction of native laccase with HA under non-denaturing conditions has been carried out.
Therefore, copper dissociation from laccase in the presence of HA can hardly occur in our experiments.

The dynamic of laccase activity at $\mathrm{pH} 5.0$ and 6.5 (Figure 6) was characterized with two stages, namely, with an activation and an inhibition stages. This effect supposed to be connected with a rearrangement of laccase active center as well as with inter transition of laccase forms existing in the solution. The peak of maximum laccase activity was observed within $1-3$ hours for laccase both at $\mathrm{pH} 5.0$ and $\mathrm{pH}$ 6.5. In the presence of HA the peak of activation was shifted to 12 hours at both $\mathrm{pH}$ studied. This finding was probably attributed to the conformational changes in laccase structure due to its association with HA.

On the second stage gradual decrease in enzyme activity along with time of incubation was observed. Laccase activity after 72 hours of incubation decreased to $72 \%$ and $70 \%$ compared to initial activity at $\mathrm{pH} 5.0$ and 6.5 , respectively. In the presence of HA those values were $89 \%$ and $99 \%$. Compared to the maximum-recorded values of laccase activity, laccase activity at the end of experiment reduced to $63 \%$ or $52 \%$ at $\mathrm{pH} 5.0$ or 6.5 , while in the presence of HA enzyme activity was $78 \%$ and $71 \%$, respectively. So, laccase activity was concluded to be stabilized in the presence of coal HA.

So, the complex formation between laccase and HA 

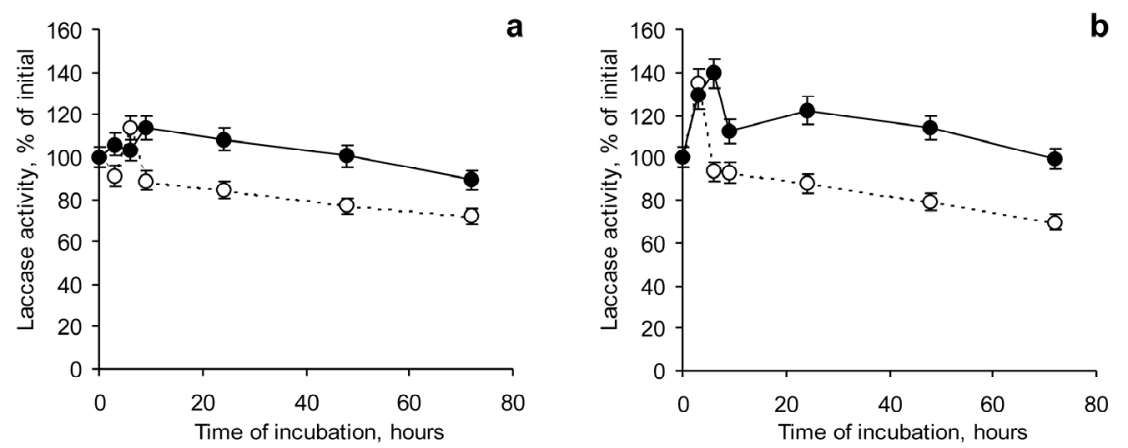

Figure 6. Dynamics of laccase activity solely (dotted lines) and in the presence of HA (firm lines) at pH 5.0 (a) and 6.5 (b). Bars represent standard deviations.

with preservation of laccase activity has been established. Assuming the stability of HA-laccase complex under conditions that provided compensation of partial negative charge both of laccase and HA, ionic interaction between those compounds can be excluded. On the other hand, IEF data allowed concluding on the non covalent binding. The association between HA and laccase by weak dispersive forces such as hydrophobic, van der Waals, $\pi-\pi$, and others was therefore hypothesized. The obtained data showed also that the interaction of laccase with HA included both complex formation and direct partial oxidation of HA structural fragments.

\section{Acknowledgements}

Authors thank Dr. Elena Stepanova for her kind assistance in fungi cultivation and laccase extraction and purification and Elena Belyaeva for the SEC measurements. This work was partly supported by the Ministry of education and science of Russia in the framework of the Federal Targeted Program "Scientific and research and educational cadres of innovative Russia in 2009-2013" (Agreement \#8111).

\section{REFERENCES}

[1] E. M. Thurman, "Organic Geochemistry of Natural Waters,” Martinus Nijhof/Dr. W. Junk Publishers, Dordrecht, 1985.

[2] D. S. Orlov, "Soil Humic Acids and General Theory of Humification", Moscow State University Publisher, Moscow, 1990.

[3] C. E. Clapp, M. H. B. Hayes and R. S. Swift, "Isolation, Fractionation, Functionalities, and Concepts of Structure of Soil Organic Macromolecules," In: A. J. Beck, K. C. Jones, M. B. H. Hayes and U. Mingelgrin, Eds., Organic Substances in Soil and Water: Natural Constituents and Their Influence on Contaminant Behaviour, Royal Society of Chemistry, Cambridge, 1993, pp. 31-69.

[4] G. Masciandaro and B. Ceccanti, "Assessing Soil Quality in Different Agro-Ecosystems through Biochemical and Chemico-Structural Properties of Humic Substances," Soil and Tillage Research, Vol. 51, No. 1-2, 1999, pp. 129137. doi:10.1016/S0167-1987(99)00056-2

[5] E. Benitez, H. Sainz and R. Nogales, "Hydrolytic Enzyme Activities of Extracted Humic Substances during the Vermicomposting of a Lignocellulosic Olive Waste," Bioresource Technology, Vol. 96, No. 7, 2005, pp. 785-790. doi:10.1016/j.biortech.2004.08.010

[6] A. Messerschmidt, "Multi-Copper Oxidases," World Scientific, Singapore, 1997.

[7] F. Xu, "Recent Progress in Laccase Study: Properties, Enzymology, Production, and Applications," In: M. C. Flickinger and S. W. Drew, Eds., Encyclopedia of Bioprocessing Technology: Fermentation, Biocatalysis, and Bioseparation, John Wiley \& Sons, New York, 1999, pp. 1545-1554.

[8] L. Gianfreda, F. Xu and J.-M. Bollag, "Laccases: A Useful Group of Oxidoreductive Enzymes," Bioremediation Journal, Vol. 3, No. 1, 1999, pp. 1-25.

[9] S. A. Gomes, J. M. Nogueira and M. J. Rebelo, “An Amperometric Biosensor for Polyphenolic Compounds in Red Wine," Biosensors and Bioelectronics, Vol. 20, No. 6, 2004, pp. 1211-1216. doi:10.1016/j.bios.2004.05.013

[10] T. Sonoki, S. Kajita, S. Ikeda, M. Uesugi, K. Tatsumi, Y. Katayama and Y. Iimura, "Transgenic Tobacco Expressing Fungal Laccase Promotes the Detoxification of Environmental Pollutants," Applied Microbiology and Biotechnoogy, Vol. 67, No. 1, 2005, pp. 138-142. doi:10.1007/s00253-004-1770-8

[11] R. Bourbonnais and M. G. Paice, "Enzymatic Delignification of Kraft Pulp Using Laccase and a Mediator," Tappi Journal, Vol. 79, No. 6, 1996, pp. 199-204.

[12] C. L. Crestini and D. S. Argyropoulos, "The Early Oxidative Biodegradation Steps of Residual Kraft Lignin Models with Laccase," Bioorganic and Medicinal Chemistry, Vol. 6, No. 11, 1998, pp. 2161-2169. doi:10.1016/S0968-0896(98)00173-4

[13] A. Ortega-Clemente, C. Estrada-Vazquez, F. EsparzaGarcia, S. Caffarel-Mendez, N. Rinderknecht-Seijas and H. M. Poggi-Varaldo, "Integrated Biological Treatment of Recalcitrant Effluents from Pulp Mills," Water Science and Technology, Vol. 50, No. 3, 2004, pp. 145-156.

[14] P. Schneider and A.H. Pedersen, "Enhancement of Laccase Reaction," PCT International Patent WO 95/01426, European Patent Office, Munich, 1995. 
[15] R. C. Senan and T. E. Abraham, "Bioremediation of Textile Azo Dyes by Aerobic Bacterial Consortium-Aerobic Degradation of Selected Azo Dyes by Bacterial Consortium," Biodegradation, Vol. 15, No. 4, 2004, pp. 275-280. doi:10.1023/B:BIOD.0000043000.18427.0a

[16] S. Böhmer, K. Messner and E. Srebotnik, "Oxidation of Phenanthrene by a Fungal Laccase in the Presence of 1hydroxybenzotriazole and Unsaturated Lipids," Biochemical and Biophysical Research Communications, Vol. 244, No. 1,1998, pp. 233-238. doi:10.1006/bbrc. 1998.8228

[17] M. A. Pickard, R. Roman, R. Tinoco and R. VazquezDuhalt, "Polycyclic Aromatic Hydrocarbon Metabolism by White Rot Fungi and Oxidation by Coriolopsis gallica UAMH 8260 Laccase," Applied and Environmental Microbiology, Vol. 65, No. 9, 1999, pp. 3805-3809.

[18] C. Johannes, A. Majcherczyk and A. Hüttermann, "Degradation of Anthracene by Laccase of Trametes versicolor in the Presence of Different Mediator Compounds," Applied Microbiology and Biotechnology, Vol. 46, No. 3, 1996, pp. 313-317.

[19] A. Majcherczyk, C. Johannes and A. Hüttermann, "Oxidation of Polycyclic Aromatic Hydrocarbons (PAH) by Laccase of Trametes versicolor," Enzyme and Microbial Technology, Vol. 22, No. 5, 1998, pp. 335-341. doi:10.1016/S0141-0229(97)00199-3

[20] M. J. Han, H. T. Choi and H. G. Song, "Degradation of Phenanthrene by Trametes versicolor and Its Laccase," Journal of Microbiology, Vol. 42, No. 2, 2004, pp. 94-98.

[21] F. S. Sariaslani, J. M. Beale Jr. and P. Rosazza, "Oxidation of Rotenone by Polyporus anceps Laccase," Journal of Natural Products, Vol. 47, No. 4, 1984, pp. 692-697.

[22] G. Amitai, R. Adani, G. Sod-Moriah, I. Rabinovitz, A. Vincze, H. Leader, B. Chefetz, L. Leibovitz-Persky, D. Friesem and Y. Hadar, "Oxidative Biodegradation of Phosphorothiolates by Laccase," FEBS Letters, Vol. 438, No. 3, 1998, pp. 195-200. doi:10.1016/S0014-5793(98)01300-3

[23] S. Kawai, T. Umezawa and T. Higuchi, "Oxidation of Methoxylated Benzyl Alcohols by Laccase of Coriolus versicolor in the Presence of Syringaldehyde," Wood Research, Vol. 76, 1989, pp. 10-16.

[24] E. Fritz-Langhals and B. Kunath, "Synthesis of Aromatic Aldehydes by Laccase-Mediator Assisted Oxidation," Tetrahedron Letters, Vol. 39, No. 33, 1998, pp. 5955-5956. doi:10.1016/S0040-4039(98)01215-5

[25] A. Potthast, T. Rosenau, C. L. Chen and J. S. Gratzl, "A Novel Method for the Conversion of Benzyl Alcohols to Benzaldehydes by Laccase-Catalysed Oxidation," Journal of Molecular Catalysis A: Chemical, Vol. 108, No. 1, 1996, pp. 5-9. doi:10.1016/1381-1169(95)00251-0

[26] K.-H. Kang, J. Dec, H. Park and J.-M. Bollag, "Transformation of the Fungicide Cyprodinil by a Laccase of Trametes villosa in the Presence of Phenolic Mediators and Humic Acid," Water Research, Vol. 36, No. 19, 2002, pp. 4907-4915. doi:10.1016/S0043-1354(02)00198-7

[27] M.-Y. Ahn, J. Dec, J.-E. Kim and J.-M. Bollag, "Treatment of 2,4-dichlorophenol Polluted Soil with Free and Immobilized Laccase," Journal of Environmental Quality, Vol. 31, No. 5, 2002, pp. 1509-1515.
[28] R. M. Fakoussa and P. J. Frost, "In Vivo Decolorisation of Coal-Derived Humic Acids by Laccase Excreting Fungus Trametes versicolor," Applied Microbiology Biotechnology, Vol. 52, No. 1, 1999, pp. 60-65.

[29] Y.-S. Keum and Q. X. Li, "Copper Dissociation as Mechanism of Fungal Laccase Denaturation by Humic Acid," Applied Microbiology and Biotechnology, Vol. 64, No. 4, 2004, pp. 588-592. doi:10.1007/s00253-003-1460-y

[30] A. N. Kovalenko, M. V. Youdov, I. V. Perminova and V. S. Petrosyan, "Synthesis and Characterization of Humic Derivatives Enriched with Hydroquinoic and Catecholic Moieties," Proceedings of the XII International Meeting of IHSS Humic Substances and Soil and Water Environment, Sao-Pedro, 25-30 July 2004, pp. 472-473.

[31] O. V. Koroleva, E. V. Stepanova, V. P. Gavrilova, N. S. Yakovleva, E. O. Landesman, I. S. Yavmetdinov and A. I. Yaropolov, "Laccase and Mn-peroxidase Production by Coriolus hirsutus Strain 075 in a Jar Fermenter," Journal of Bioscience and Bioengineering, Vol. 93, No. 5, 2002, pp. 449-455.

[32] O. Koroleva (Skorobogat'ko), E. Stepanova, V. Gavrilova, O. Morozova, N. Lubimova, A. Dzchafarova, A. Yaropolov and A. Makower, "Purification and Characterization of the Constitutive Form of Laccase from the Basidiomycete Coriolus hirsutus and Effect of Inducers on Laccase Synthesis," Biotechnology and Applied Biochemistry, Vol. 28, No. 1, 1998, pp. 47-54.

[33] R. Westermeier, "Electrophoresis in Practice," VCH Verlagsgesellschaft, Weinheim and VCH Publishers Inc., New York, 2001.

[34] C. G. Kowalenko, L. J. P. van Vliet, G. Derksen and S. $\mathrm{Yu}$, "Limitations of Methods for Preserving Ammonium in Agricultural Runoff Samples," Canadian Journal of Soil Science, Vol. 82, No. 4, 2002, pp. 439-444.

[35] I. V. Perminova, F. H. Frimmel, D. V. Kovalevskii, G. Abbt-Braun, A. V. Kudryavtsev and S. Hesse, "Development of a Predictive Model for Calculation of Molecular Weight of Humic Substances," Water Research, Vol. 32, No. 3, 1998, pp. 872-881. doi:10.1016/S0043-1354(97)00283-2

[36] A. V. Kudryavtsev, I. V. Perminova and V. S. Petrosyan, "Size-exclusion Chromatographic Descriptors of Humic Substances," Analytica Chimica Acta, Vol. 407, No. 1-2, 2000, pp. 193-202. doi:10.1016/S0003-2670(99)00814-4

[37] P. G. Righetti, "Isoelectric Focusing: Theory, Methodology and Applications," Elsevier Biomedical Press, Amsterdam, 1983.

[38] I. V. Perminova, "Size-Exclusion Chromatography of Humic Substances: Complexities of Data Interpretation Attributable to Non-size Exclusion Effects," Soil Science, Vol. 164, No. 11, 1999, pp. 834-840. doi:10.1097/00010694-199911000-00008

[39] O. V. Koroleva (Skorobogat'ko), E. V. Stepanova, V. P. Gavrilova, V. I. Biniukov, A. I. Jaropolov, S. D. Varfolomeyev, F. Scheller, A. Makower and A. Otto, "Laccase of Coriolus zonatus Isolation, Purification and Some Physico-Chemical Properties," Biotechnology and Applied Biochemistry, Vol. 76, No. 2, 1999, pp. 115-127.

[40] A. Cozzolino and A. Piccolo, "Polymerization of Dissolved Humic Substances Catalyzed by Peroxidase. Ef- 
fects of $\mathrm{pH}$ and Humic Composition," Organic Geochemistry, Vol. 33, No. 3, 2002, pp. 281-294. doi:10.1016/S0146-6380(01)00160-7

[41] S. H. Van Erp, E. O. Kamenskaya and Y. L. Khmelnitsky, "The Effect of Water Content and Nature of Organic Solvent on Enzyme Activity in Low-Water Media. A Quantitative Description," European Journal of Biochemistry, Vol. 202, No. 2, 1991, pp. 379-384. doi:10.1111/j.1432-1033.1991.tb16385.x

[42] J. Rodakiewicz-Nowak, J. Haber, N. Pozdnyakova, A. Leontievsky and L. A. Golovleva, "Effect of Ethanol on Enzymatic Activity of Fungal Laccases," Bioscience Reports, Vol. 19, No. 6, 1999, pp. 589-600. doi:10.1023/A:1020223130115

[43] J. Rodakiewicz-Nowak, "Phenols Oxidizing Enzymes in Water-Restricted Media," Topics in Catalysis, Vol. 11-12, No. 1-4, 2000, pp. 419-434.
doi:10.1023/A:1027291629302

[44] U. Temp, H. Meyrahn and C. Eggert, "Extracellular Phenol Oxidase Pattern during Depolymerization of LowRank Coal by Three Basidiomycetes," Biotechnology Letters, Vol. 21, No. 4, 1999, pp. 281-287. doi:10.1023/A:1005491818192

[45] R. McMillin and M. K. Eggleston, "Bioinorganic Chemistry of Laccase," In: Messerschmidt, Ed., Multicopper Oxidases, World Scientific, Singapore, 1997, pp. 129166.

[46] O. V. Koroleva, E. V. Stepanova, V. P. Gavrilova, V. I. Biniukov and A. M. Pronin, "Comparative Characterization of Methods for Removal of $\mathrm{Cu}$ (II) from the Active Sites of Fungal Laccases," Biochemistry-Moscow, Vol. 66, No. 9, 2001, pp. 960-966. doi:10.1023/A:1012357223083 